\title{
Publicidad en la era de la postproducción: el producto virtualizado
}

\author{
Juan García CREGO ${ }^{1}$ \\ Alberto GarCía García ${ }^{2}$ \\ Universidad Complutense de Madrid
}

Recibido: $20 / 11 / 2014$

Aceptado: 31/12/2014

\section{Resumen}

El producto publicitario y su acabado final han sido muy poco estudiados en la investigación sobre publicidad. Este estudio pretende aportar algo de luz a este vacío.

Todo producto publicitario en la actual Era Digital debe crearse tanto para los medios convencionales (sobre todo en el ámbito de internet) como para los medios no convencionales, a partir de la transversalidad del producto.

La única manera de conseguir esto, es que ese producto sea moldeable, manipulable e intercambiable de un medio a otro. Para alcanzar este objetivo es necesario conocer las posibilidades que nos da la postproducción.

El objetivo principal de este estudio es desvelar como la postproducción, el mundo del CGI (Computer Generated Imagery), de la infografía en definitiva de la imagen computacional, reina en la publicidad audiovisual actual.

Otro objetivo planteado es hacer un llamamiento a los profesionales de la publicidad del futuro para que conozcan esas herramientas y para ofrecer a los investigadores del presente una breve guía de las diversas formas de uso de los elementos de la postproducción.

Palabras clave: Postproducción, Publicidad, Spot Audiovisual, Spot impreso, Simulacro.

1 Juan García Crego es Profesor Ayudante Doctor del Departamento de Comunicación Audiovisual en la Facultad de Ciencias de la Información. Universidad Complutense de Madrid (España) (juangarc@ccinf.ucm.es).

2 Alberto García García es Profesor Contratado Doctor del Departamento de Comunicación Audiovisual en la Facultad de Ciencias de la Información. Universidad Complutense de Madrid (España)(algarci@ccinf.ucm.es). 


\title{
Publicity In The Age Of Postproduction: the Virtual Product
}

\begin{abstract}
The advertising material and its finished product has been very little studied in advertising research. This study aims to fill that gap.

All advertising products in the current Digital Era must be created for both the mainstream media (especially in the field of internet) to unconventional ways, from the transversality of the product.

The only way to achieve this, is that this product is malleable, manipulable and interchangeable from one medium to another. To achieve this goal it is necessary to know the possibilities that we postproduction.

The main objective of this study is to reveal as post-production, the world of CGI (Computer Generated Imagery), computer graphics ultimately computational image reigns in the current broadcast advertising. Another goal we set ourselves is to appeal to the advertising professionals of the future to know these tools and provide researchers present a brief guide to the various ways to uncover the elements of the post. Keywords: Postproduction, Publicity, Audiovisual Spot, Advertising, Simulation.
\end{abstract}

\section{Producto publicitario, el resultado final}

El acabado de cualquier producto publicitario siempre ha sido una de las principales preocupaciones y ocupaciones de los responsables de dicho producto. El receptor del mensaje publicitario tiene que ver el producto en el estado de presentación óptima. Sin defecto y sin tara.

Desde las primeras muestras de publicidad, desde sus orígenes en la época de las revoluciones ${ }^{3}$, esto se ha cumplido de una manera inequívoca. El producto que se vende siempre tiene que lucir.

En los rodajes de spots publicitarios, ya sea la lata de cerveza, el rollo de papel, etc, es fundamental la figura del encargado del producto. Sin duda ese experto es el primer paso de la postproducción. Pero esta figura está siendo cada vez más relegada por el retoque informático que nos da un producto más apetecible.

En este estudio vamos a intentar mostrar como en la actual Era Digital, donde las nuevas tecnologías representan un nuevo paradigma de enunciación publicitaria, todo producto es simplemente perfecto, maleable y eterno.

\section{Hipótesis}

El cien por cien de la publicidad que se produce en la actualidad es sometida a un proceso de postproducción que la configura y le permite pasar de los medios convencionales a los no convencionales.

La invisibilidad de la postproducción, como recurso necesario y siempre presente de la publicidad global. La hipótesis de los "hombrecillos verdes" (informáticos o técnicos CGI) que, con su magia, crean un producto publicitario perfecto.

\section{Estado de la cuestión. Delimitando el concepto}

"Postproducción" es un término técnico utilizado en el mundo de la televisión, el cine y el video. Designa el conjunto de procesos efectuados sobre un material grabado: el montaje, la inclusión de otras fuentes visuales o sonoras, el subtitulado, las voces en

${ }^{3}$ Eguizábal, R. (2011): Historia de la publicidad. Madrid, Editorial Fragua, 20. 
off, los efectos especiales. Como un conjunto de actividades ligadas al mundo de los servicios y del reciclaje, la postproducción pertenece pues al sector terciario, opuesto al sector industrial o agrícola - de producción de materias en bruto"4

Nicolas Bourriaud, autor de esta definición, parece referirse solo a la imagen en movimiento en los grandes medios ya que la teoría de la estética relacional ${ }^{5}$ que él propugna, se centra en el arte y su relación con el espectador. Pero desde este artículo vemos que es posible introducir esta definición de postrproducción también en la publicidad. De hecho Barriaud hace hincapié en esa interacción de la publicidad y el arte.

Evidentemente, la postproducción del producto publicitario es un término tan amplio que no es posible analizarlo en la extensión de un artículo como éste. Vamos a centrarnos en abordar la postproducción del producto impreso y del producto audiovisual, que conducen al camuflaje de lo real para extrapolarlo a cualquier medio y mostrar el producto en las condiciones mejores y más apetecibles posibles para el consumidor, como destinatario último.

La relación ya tratada en otro número de esta revista entre el arte y publicidad es un tema de investigación y controversia. El modo de usar el producto, ese producto industrial, elaborado de una manera lineal en una fábrica para su uso masivo y que, en algunos casos, es utilizado como un objeto de arte es algo que enseñaron las vanguardias y que se ha replicado en el arte pop y en los artes de final de siglo veinte y comienzo del veinte uno. Esta forma de usar los objetos puede considerarse sin lugar a duda una forma de postproducción. Los paisajes imaginarios ${ }^{6} \mathrm{y}$ los objetos no existentes será lo que defina la publicidad actual.

También hay que tener en cuenta como los medios convencionales, hablamos sobre todo de la red, de internet, se benefician de la plasticidad de la postrproducción para llevar el anuncio a cualquier medio no pensado hasta ese momento. El producto postproducido puede ser replicado de una manera infinita.

A su vez los medios no convencionales también han sufrido una profunda transformación con las técnicas de postproducción que les ha permitido llegar a lugares y posibles consumidores diferentes, tanto en la diversidad del consumidor como en el medio a través del cual le llega el producto final (televisión, tableta, ordenador, teléfono) que apoyan la universalidad del mensaje tanto escrito como audiovisual En este sentido, "la compatibilidad existente entre formatos de reproducción de vídeo redunda en una mayor convergencia en los medios digitales"', ya sean convencionales o no, atendiendo a la clasificación que hace el estudio Infoadex ${ }^{8}$, en el que la publicidad en internet se considera publicidad convencional.

\footnotetext{
${ }^{4}$ Bourriaud, N. (2007): Postproducción. Buenos Aires Adriana Hidalgo Editores, 7.

5 Bourriaud, N. (2006): Estética relacional. Buenos Aires Adriana Hidalgo Editores, 8

${ }^{6}$ Eguizabal, R. (2012): Visiones ideales del consumo. Pensar la publicidad. Núm. Especial: Arte, Publicidad y Vida Cotidiana. Vol 6. Universidad Complutense. Madrid, 200.

7 Aguado Guadalupe, G y García García, A (2009): Del Word-of-mouth al Marketing viral: aspectos claves de la comunicación a través de redes sociales. Revista Comunicación y Hombre. Número 5, 3-13.

${ }^{8}$ InfOAdEX (2014): Estudio Infoadex de la inversión publicitaria en España 2014. Infoadex, Madrid.
} 


\subsection{Postmodernidad-Postproducción}

Uno de los ámbitos preferidos donde la postmodernidad mostró y muestra todo su argumentario teórico (si alguna vez lo tuvo) y visual es en la publicidad. Evidentemente no se puede equiparar un término filosófico como es la postmodernidad con uno que podríamos considerar técnico, como es el de la postproducción. Pero podríamos plantearnos hasta qué punto todo producto audiovisual en la era postmoderna, se puede considerar como producto postproducido.

El concepto programa de software se va a convertir en el paradigma configurador de una nueva forma de entender la publicidad. Todos los productos publicitarios se van a someter a uno o varios programas que darán su resultado final en los diversos formatos. Que nos darán una ideación u cuerpo no real. El simulacro que se convierte en hiperrealidad va a ser un factor definitorio y definitivo e de la publicidad, siendo en ella donde se va a producir de una manera más visible.

"La simulación no corresponde a un territorio, a una referencia, a una sustancia, sino que es la generación por los modelos de algo real sin origen ni realidad: lo hiperreal. "'

El texto de Braudillard retumba en nuestras cabezas mientras vemos como sus palabras se han convertido en realidad de una manera preclara en el mundo del audiovisual.

Lo que queremos establecer en este punto es la consecución de uno de los principios fundamentales de la publicidad; hablamos de despertar el deseo en el posible cliente. Todos estos procesos de construcción buscan, sin ningún género de duda, hacer que el consumidor quiera tener el objeto, poseerlo y usarlo. Esta idea se definiría como la articulación del deseo del consumidor mediante un ejercicio del visionado ideal del producto. También aquí podemos hablar de el hedonismo o cultura del placer que son rasgos que definen la postmodernidad ${ }^{10} \mathrm{y}$ beneficiarían la incitación de ese deseo.

La comunicación como simulacro es una de las características de esa condición postmoderna ${ }^{11}$. En la actualidad se ha llegado a una situación donde en la mayoría de anuncios publicitarios ya no se trabaja apenas con el producto real, sino con una representación virtual del mismo. Y, es aquí, principalmente, donde la postproducción y las técnicas asociadas a la misma que son cada vez más precisas y sofisticadas, entran como una parte fundamental en el proceso creativo y de producción del spot publicitario.

La diferencia entre lo verdadero y lo verosímil se verá cada vez más en entredicho, por la sucesiva utilización de esa imagen computacional que quiere borrar su referente real y dar sensación de verosimilitud, no de verdad ${ }^{12}$. Es interesante como este tema esta tan de actualidad como lo estaba en la época de Platón o Aristóteles.

\footnotetext{
9 Baudrillard, J. (1978): Cultura y Simulacro. Barcelona, Editorial Kairós, 9.

10 Lipovetsky, G. (2002): La era del vacío. Ensayo sobre el individualismo contemporáneo. Barcelona, Anagrama, 22.

${ }^{11}$ García Fernandez, J. V. (2008): Del fracaso amoroso. De la belleza. De la posmodernidad. Oviedo, KRK Ediciones, 347.

12 Moreno, I. (2003): Narrativa audiovisual publicitaria. Barcelona, Editorial Paidós, 31.
} 


\section{El reino de la postproducción}

Sin lugar a duda, el predominio de la postproducción es absoluto en el ámbito del spot audiovisual.

En la publicidad occidental la realización del spot audiovisual ha contado desde sus inicios con grandes directores de cine que eran estudiados tanto por sus obras cinematográficas como por sus obras publicitarias. La postproducción cinematográfica ha sido siempre considerado y abordado como una cuestión puramente técnica, una parte imprescindible de la narración cinematográfica pero sin un reconocimiento al mismo nivel, por ejemplo, que la dirección o el guión. En publicidad el acabado final ha contado también con grandes empresas (las mismas que se encargan de la postproducción para cine o televisión). En España hablamos de empresas como Telson ${ }^{13}$ o El Ranchito ${ }^{14}$, etc., que en sus páginas web exponen sus trabajos en publicidad y en cine. Estas empresas, a pesar de su importancia en la finalización y puesta en el mercado de los diversos productos audiovisuales, son consideradas como un mero eslabón más de la cadena y nadie repara en ellas como lugares de creación final, ya que el producto audiovisual se configura allí.

\subsection{El videoclip abrió el camino}

Tenemos que tener en cuenta y entender el videoclip como un producto publicitario más, es decir, como producto económico dentro de la industria musical occidental ${ }^{15}$. Es sin duda el medio que utilizan los grupos musicales para darse a conocer, dar a conocer su nuevo Single o su nuevo LP, CD, Mp3 o FLAC

El último gran salto en la estrecha relación entre la publicidad y la industria del videoclip se refiere al nuevo disco del grupo irlandés de rock - pop U2, que aunaron el estreno de su nuevo disco con la presentación del iphone 6 o viceversa. El anuncio (spot audiovisual en televisión y en la página web del producto) del nuevo iphone 6 , sirvió como base para una campaña de mercadotecnia innovadora, basada en la inclusión gratuita del disco en el dispositivo digital, pudiéndose descargar de manera gratuita tras el registro a la plataforma iTunes.

De esta manera entendemos que el videoclip musical está más vivo que nunca, no solo para los grandes o pudientes grupos. Las pequeñas bandas se han aprovechado del abaratamiento de los programas de postproducción. Eso sí, las grandes bandas cuentan con presupuestos que están a la par de las mejores ficciones hollywodienses e incluso son dirigidos por directores que habitualmente trabajan en Hollywood.

Esa democratización de los medios a su vez ha abaratado la producción de los videoclips a niveles mínimos. Siendo muy común la aparición de nuevos ídolos de masas gracias a simples grabaciones, postrproducidas mínimamente y subidas a youtube. El equilibrio entre los necesarios recortes en los costes de producción y la necesaria facilidad en la difusión del producto, hacen del universo digital el medio clave para la creación de productos finales (ya sean artistas de la música o productos publicitados)

\footnotetext{
13 Telson: http://www.telson.es/. Web visitada el 10/09/2014.

14 El ranchito: http://elranchito.es/. Web visitada el 10/09/2014.

15 Viñuela SuÁrez, E. (2009): El videoclip en España. Madrid, Ediciones del ICCMU, 69.
} 
convertidos en elementos de difusión masiva con capacidad de generar atención específica en públicos específicos. Este valor constituye, dentro de la producción de spots publicitarios, un paradigma fundamental del valor de la postproducción como conjunto de técnicas responsables del acabado final. No podemos olvidarnos de los pioneros de este campo de la postproducción en video clip, que se convirtió en industria al inaugurarse, en 1981, la cadena MTV, que es el acrónimo de Music Televisión. Una cadena de cable que surge en los Estados Unidos y que para ser lanzada conto con la aportación del autor publicitario y creativo George Lois que realizó la campaña "I want my MTV". Una campaña de carácter explosivo que contaba con grandes figuras de la música rock y pop de aquellos días. Su concepto de Big Idea va a crear una imaginería que cambiaría la publicidad musical, a partir de conceptos como la venta musical a través del videoclip. Es, desde esta cadena, donde se comienza a emitir vídeos de los grupos que sonaban en aquellos años en las listas de éxitos, muchos de ellos con el respaldo de una gran compañía que veía en este medio la forma de llegar a más lugares y mantener una clara relación con las vanguardias de diseño y musicales de esos años ${ }^{16}$. No olvidemos que esta campaña publicitaria corresponde a la compra por la compañía VIACOM de la cadena MTV.

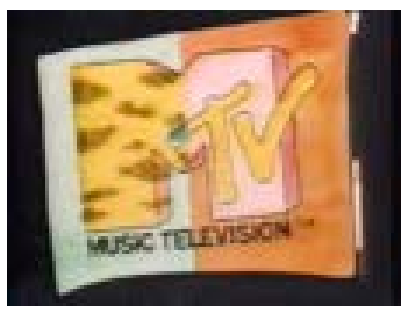

Foto 1

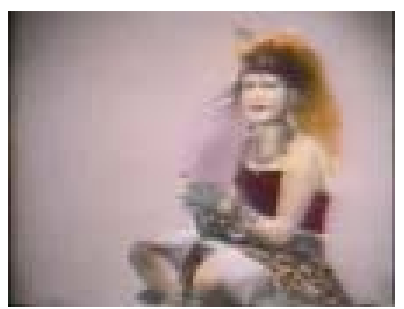

Foto 4

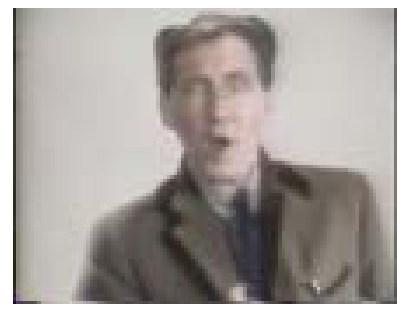

Foto 7

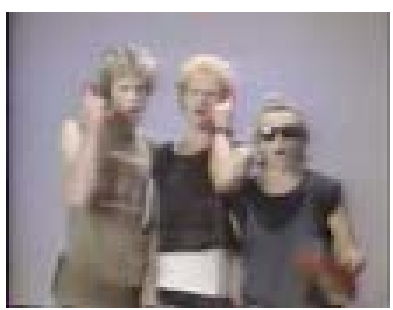

Foto 2

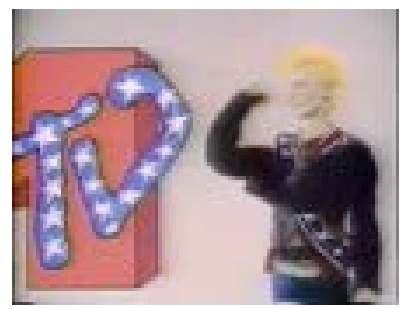

Foto 5

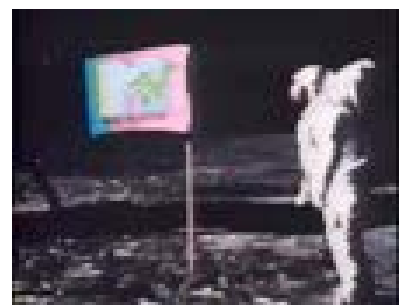

Foto 8

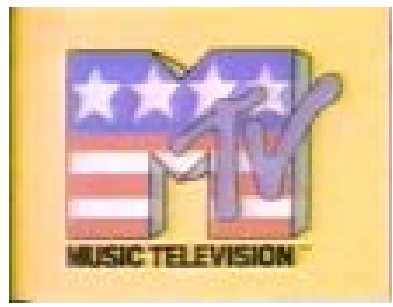

Foto 3

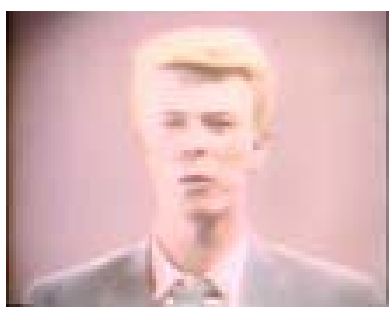

Foto 6

16 Hervás Ivars, C. (2002): El diseño gráfico en televisión. Madrid, Ediciones Cátedra, 7. 
Como vemos en las imágenes, la marca MTV aparece de una manera flexible, manipulable e intercambiable, gracias a la postproducción. También podemos atisbar el claro target que esta cadena buscaba. Desde los adolescentes amantes de la última diva de la música pop con la actriz Cindy Lauper (foto4) o al grupo más actual como era The Police (foto2). La vertiente transgresora de los seguidores de la música Punk con Billy Idol (foto 5).Y sin olvidar a los adultos que habían crecido en la generación de la música rock con artistas ya consagrados como el cantante británico David Bowie (foto 6) o Pete Townshend guitarrista de los la banda de música rock The Who (foto 7).

El conjunto de música rock británico Dire Straits realizan un videoclip en 1985 dirigido por Steve Barron, un director responsable de algunos de los vídeos más icónicos de los años ochenta del siglo pasado. Este director realizó un vídeo en el que la postproducción iba a impactar a las audiencias y por extensión a los consumidores. Sin lugar a dudas esta pieza visual marcará un antes y un después en este tipo de producto publicitario. La canción que publicitaba se llamaba Money for nothing y pertenecía al disco Brothers in arms. Todo el vídeo está elaborado con técnicas de imagen por ordenador, con un hoy en día rústico CGI (Computer Generated Imagery). En su momento supuso, no obstante, un acto de vanguardia en toda la creación audiovisual.

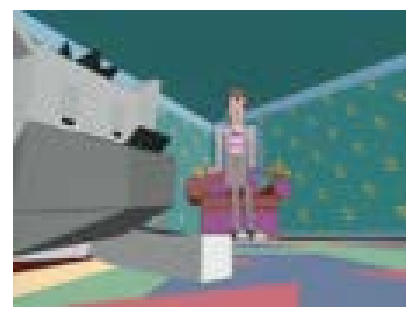

Foto 9

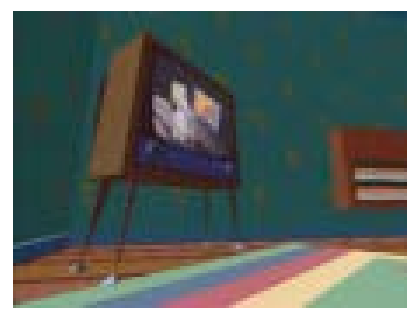

Foto 10

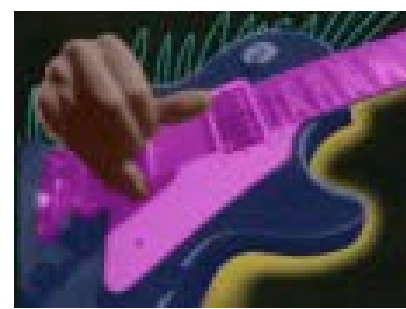

Foto 11

En el propio vídeo aparece la campaña publicitaria de la que hemos hablado de la cadena MTV creado por George Lois (Foto 10). Un ejemplo de esa transversalidad que ofrece la postproducción. En el mismo, desde las formas creadas por ordenador, así como el tratamiento de la imagen real sobre la que se incrustan diversas animaciones computacionalmente generadas suponen un paso pionero en la postrproducción de un producto. En este caso cultural.

La siguiente gran aportación al campo de la postproducción, en el ámbito del videoclip y por extensión al de la publicidad, es el caso de otro artista de la música pop como fue Michael Jackson. Hablamos del videoclip Black or White, dentro de la promoción de su álbum Dangerous, estrenado el 11 de noviembre del año 1991. Dirigido por el nunca bien ponderado John Landis, que ya había dirigido el videoclip Thriller, un fenómeno mundial en el inicio de la era de la globalización, que también desplegaba una gran carga de postproducción en sus imágenes. En este caso lo relevante será cómo se va a utilizar la imaginería CGI en un elemento que se denomina la técnica del morphing. 


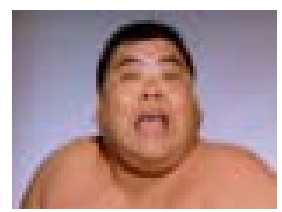

Foto 12

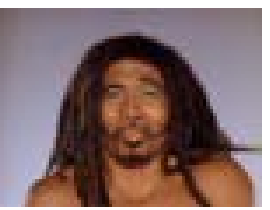

Foto 17

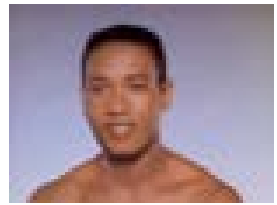

Foto 22

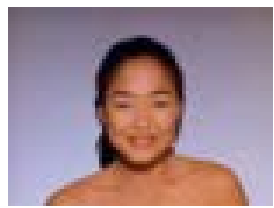

Foto 27

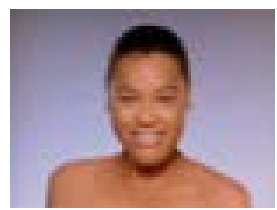

Foto 13

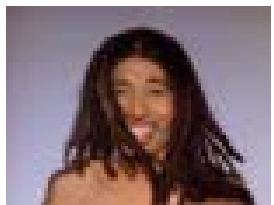

Foto 18

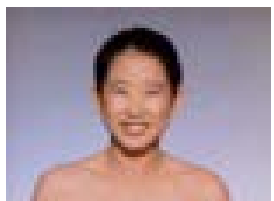

Foto 23

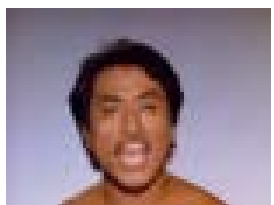

Foto 28

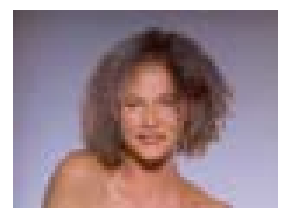

Foto 32

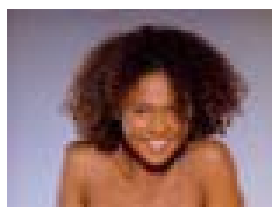

Foto 33

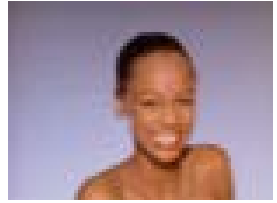

Foto14

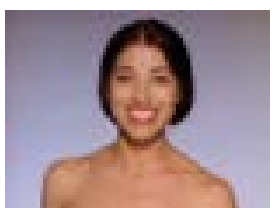

Foto 19

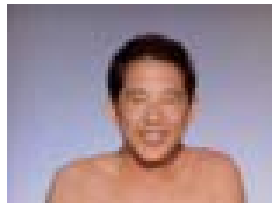

Foto 24

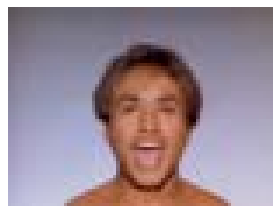

Foto 29

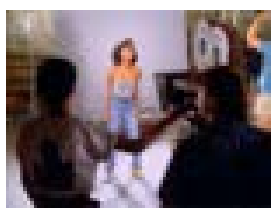

Foto 34

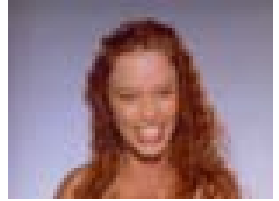

Foto 15

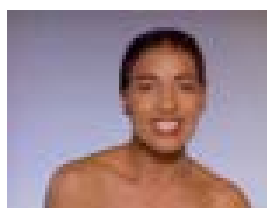

Foto 20

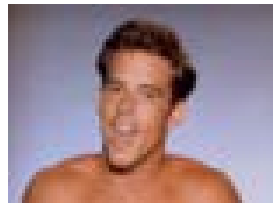

Foto 25

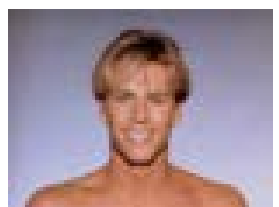

Foto 30

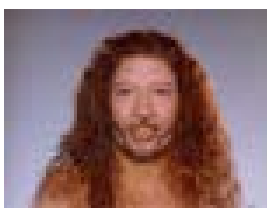

Foto 16

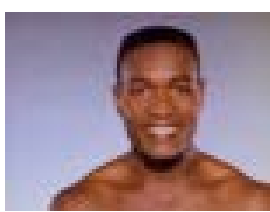

Foto 21

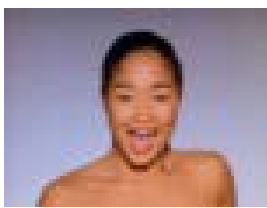

Foto 26

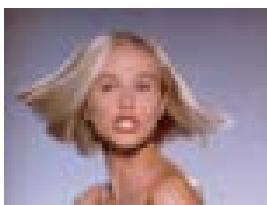

Foto 31

En el vídeo de Michael Jackson, en su parte final a partir del minuto 5:24, comienza esta sucesión de 13 personajes de distintas razas que van transformándose unos en otros de una manera dinámica al ritmo de la música del artista. La parte final del video nos desvela la técnica cinematográfica de la pantalla azul e incluso vemos al director de videoclip felicitando a su artista.

Esa técnica se comenzó a usar en el cine con la película Abyss (Abyss, 1989) dirigida por James Cameron. En la misma, el agua está modelada de una manera que coge forma y se convierte en un personaje más del film: Previamente, hubo un primer 
acercamiento del MORPHING, que el mismo director retomaría en Terminator 2, el juicio final (Terminator 2, The Judgment Day, 1991). Estrenado el 1 de julio de ese año 1991. La relación entre los efectos especiales de la película y del videoclip es patente. Ambos ideados por la empresa de postproducción INDUSTRIAL LIGHT AND MAGIC (empresa propiedad de George Lucas y con la que elaboró los efectos especiales de la saga Star Wars), una de las grandes películas innovadoras tanto en programas como en diverso aparataje técnico de grabación. Si bien esta empresa ha trabajado más en el mundo cinematográfico, sus innovaciones técnicas se han aplicado de manera frecuente al mundo de la publicidad.

De esta manera el concepto CGI, se instaura en las narraciones audiovisuales de occidente e ira llegando cada vez más al mundo de la publicidad, al spot audiovisual. Actualmente es el principal reclamo de toda creación publicitaria.

\subsection{La publicidad impresa}

El anuncio en prensa de papel, periódico o cualquier soporte se puede considerar al 100 por 100 afectado por un proceso postproductivo que iría de las ideas y del briefing a su procesamiento por los creativos, el director arte y los profesionales del diseño que convertirán en imagen bidimensional.

El diseño es lo que reina en este tipo de publicidad, sin ningún lugar la más antigua de las que se conocen. El conocimiento de los diversos programas de composición, en la actualidad vectoriales y que permiten la manipulación del logo, la marca, el producto y todo ello desde un simple ordenador, portátil o de sobremesa. Entraríamos en ese posible concepto de Postpublicidad ${ }^{17}$.

Esta maleabilidad de la publicidad es lo que permite su transvase de los medios convencionales a los no convencionales. Por ejemplo, que una marca se quiera anunciar con solamente su logo en un periódico pero, a su vez, este logo aparezca en unas bolsas de que se entregan con la publicación. Se utilizaría el mismo fichero de trabajo de imagen tanto para una como para otra modalidad de publicidad. Una publicidad para un medio convencional como otra que no lo es.

\subsection{Programas que ocultan la realidad del producto}

Todo producto audiovisual al que nos enfrentamos o que queramos analizar está postproducido. No es algo reciente o que solo se haga en los últimos años; esta condición de producto postproducido está en la ontogénesis de los productos audiovisuales. Ya fuese por ser registrado por una máquina y su posterior reelaboración en laboratorios fotoquímicos, ya fuese realizado a través de rudimentarias composiciones en todo tipo de soportes físicos, etc., lo que define en la actualidad el acabado final del producto es la condición de postproducción en el reinado del CGI, es decir, de la creación de imágenes computerizadas y definitivamente, virtuales. Incluso, la imagen real, es

17 Solana, D. (2010): Postpublicidad. Reflexiones sobre una nueva cultura publicitaria en la era digital. Barcelona, Autoeditado, 200. 
tratada para convertirse en un referente de su estado ideal evitando la originalidad como característica fundamental del mismo. ${ }^{18}$

Y a su vez, las técnicas de postproducción se han popularizado de tal manera que pueden ser empleadas por cualquier persona en su casa, con equipos informáticos convencionales que no fueron creados específicamente para un uso profesional. En este sentido, cualquier Smarthpone convencional es una herramienta de creación de postrproducción.

No obstante, como en cualquier otra industria, existe un número de programas estándar sobre los que trabajar y que sirven para diferenciar el trabajo del aficionado del profesional. Aquí, es donde con toda probabilidad, ha existido el conflicto más importante en la profesión en los últimos años. La postproducción al servicio de la publicidad tiene que ser cada vez más espectacular en su acabado final, para diferenciarse de manera clara de los productos finales que las personas con acceso a estas herramientas básicas de postproducción, terminan por crear y difundir por los medios digitales. La postproducción se ha colado en el acervo común de todo las personas que nunca a han estado relacionados en la elaboración de los productos audiovisuales que consumen. Expresiones tan cercanas como:

¡A mi es@ no me engaña! ¡Es@ 1leva Photoshop!

Sin duda este programa ya es conocido por todo el mundo, y todo el mundo lo sabe reconocer en las fotografías de los diversos medios impresos que la gente consume de forma diaria. De hecho volvemos a nuestra hipótesis, que se corrobora. Toda imagen bidimensional que vemos en cualquier medio publicitaria esta al cien por cien retocada por este programa o por algún procesador de imágenes.

Los gráficos, las marcas, los títulos de los spots audiovisuales o de la prensa impresa son producidos con programas de dibujo que se denominan vectoriales. En la actualidad el más extendido sería el Illustrator que al igual que Photoshop pertenece a la empresa Adobe (que también posee programas como Flash player, que nos permite ver vídeos en distintos dispositivos computacionales o Adobe Reader que es un programa para lectura de textos). Illustrator superó a otro programa que fue el principal durante años como fue Freehand de Macromedia. Realmente esta superación no se produjo por que fuese mejor producto, si no porque Adobe compro a su competidor.

Programas de edición no lineal, que se usan para el montaje de vídeo: AVID, Adobe Premiere, Final cut a nivel profesional y a nivel más básico podemos hablar de Imovie para Mac o Windows Movie Maker para Windows.

A nivel de imágenes generada por ordenador, los CGI y 3D los programas son variados y de empresas muy distintas. Nombres como Maya, 3ds Max, E-on Vue,

${ }^{18}$ Fernández Casado, J. L., Nohales Escribano, T. (1999): Postproducción digital. Cine y vídeo no lineal San Sebastián Ed. Escuela de cine y vídeo, 9. 
Blender, Poser, Cinema4D, Houdini. Su conocimiento es para gente muy especializada en ese campo, pero cada día se hacen más accesibles. Lo que nos permite ver un futuro en el que los jóvenes creen sus propias imágenes en 3D de una manera fácil y sencilla.

Los efectos especiales a nivel doméstico y profesional de nuevo el referente es la casa Adobe con Aftereffects.

Cada programa fue diseñado con un propósito, con una utilidad. Pero es curioso como la evolución de los mismos es muy similar a todos ellos Cada versión se mejora de la anterior pero en la mayoría de las ocasiones se alcanza un punto de estabilidad. A partir de ese momento que lo que se suma son leves mejoras y se mantienen la base inicial operativa.

\subsection{La postproducción en nuestros bolsillos y en nuestras aulas}

Pero en esa nueva relación con los medios técnicos y las nuevas tecnologías, que nunca son nuevas, han dado un giro en los últimos años con la irrupción en casi todos los bolsillos de los consumidores de los smartphones. El nuevo paradigma de acercamiento al mundo computacional ya no es el ordenador, ni de sobremesa ni portátil. Son los móviles y las tabletas.

Todos estos dispositivos, sin excepción, cuentan con una cámara que permite la captura de imágenes fijas así como la grabación de vídeo. El mundo de la aplicación o apps ha permitido que cualquier usuario pueda hacer retoques básicos de postproducción sobre la propia imagen capturada, a partir de filtros preconfigurados sin muchas posibilidades de manipulación pero muy efectivos desde el punto de vista visual. De la misma manera, existen aplicaciones que permiten crear efectos especiales con los vídeos que grabamos con la cámara del dispositivo mínimo portátil. Nos sumergimos, por tanto, de manera personalizada en un mundo en postproducción continúa: podemos retocar nuestras fotos, nuestros videos o nuestros audios y, de este modo, convertirnos nosotros mismos en productos finales de publicidad.

Este nuevo perfil de creador audiovisual "por un día" va a conocer y desarrollar interés por esta nueva forma de entender la captura y representación de la realidad. Los nuevos creadores audiovisuales llegan a las aulas de los estudios primarios y luego toman la decisión en algunos casos de realizar estudios en publicidad. Estas nuevas generaciones de futuros publicistas han de ser adiestrados en el conocimiento de todas estas nuevas herramientas y ser capaces de desarrollar un discurso junto a ellas. En otros casos lo primordial sería que fuesen capaces de desenmascarar las imposiciones de la postproducción con el fin de crear algo nuevo, algo rompedor. Es decir el conocimiento para su mejor utilización. ${ }^{19}$

${ }^{19}$ García Crego, J. Y García Fernández, J. V. (2012): Teorías y Técnicas de Manipulación Humana. Madrid, Editorial Fragua. Colección Fragua Comunicación, 89. 


\section{La observación como método de desenmascaramiento. "El producto mágico"}

Para la elaboración de esta investigación nos hemos centrado en el spot audiovisual como el mundo del CGI se ha instaurado de una manera total e hemos seguido durante un periodo de tiempo las cadenas generalistas, así como en las cadenas de pago. A través de una metodología de observación directa, hemos comprobado que existe una relación directa entre la postproducción y la publicidad actual. La observación consiste en una observación aleatoria de franjas de publicidad en horarios y medios de comunicación diferentes, para tratar de descubrir todas las imágenes CGI de los spots y comprobar si realmente es tan presente como defendemos en esta investigación.

En nuestro caso cogemos como objeto de estudio un bloque de publicidad emitido por la cadena generalista CUATRO el 13 de octubre de 2014, en su franja de tarde. La duración es de 3 minutos y 12 segundos. Y se emiten doce spots.

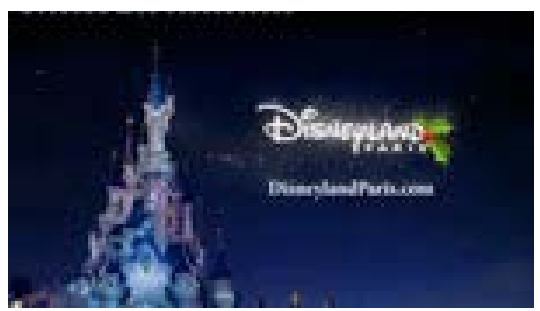

Foto. 35

Spot 1: Disneyland Paris. En él se usan imágenes de un espectáculo en el lugar que se anuncia, Disneyland. La postproducción aparece al introducir los títulos y una especie de polvo mágico que ilumina las letras. También contamos con la presencia de nieve virtual. El elemento mágico está claramente presente.

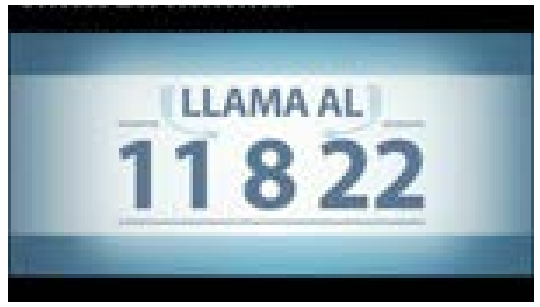

Foto. 36

Spot 2: 11822, empresa de información telefónica. En este Spot no tenemos ningún elemento CGI, salvo el rótulo final que es un rótulo fijo, sin ningún tipo de iluminación específica ni movimiento. Es llamativo que este spot cuenta con una bandas negras que indican que no ha sido concebido para televisión en su formato convencional 16:9, siempre utilizado como recurso artístico y conceptual que le hace diferenciarse a través del formato del resto de spots de la franja. 


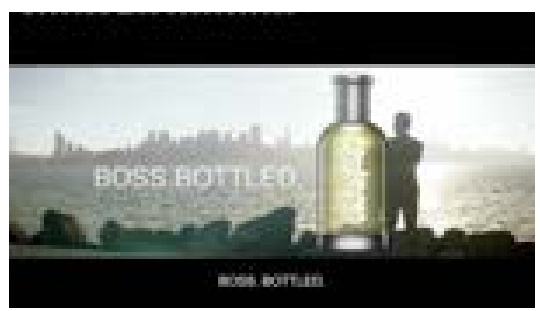

Foto. 37

Spot 3: Colonia para hombre Hugo Boss. Cuenta con la presencia del actor Gerard Butler conocido por su papel de rey Leónidas en $300(300,2007)$ dirigida por Zack Snyder. Este actor es conocido como uno de los símbolos de la masculinidad contemporánea. El anuncio tiene una factura cinematográfica con localizaciones reales, salvo que al final del mismo se nos presenta un bote de colonia ficcional donde se trasluce la imagen del actor. Es reseñable el uso de reflejos y brillos de toda manera imposibles que ocasiona la colonia en el actor. Este spot ha sido concebido para televisión aunque presentado como una película vista en televisión, además de que este formato permite ser exhibido en el ultrapanorámico cinematográfico ${ }^{20}$.

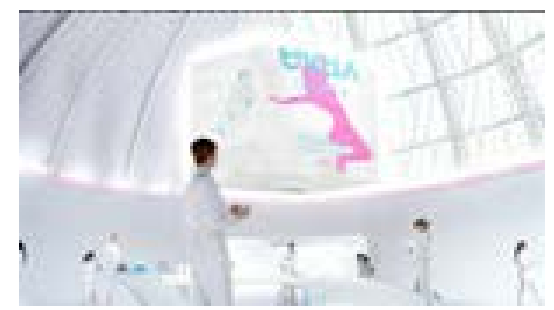

Foto. 38

Spot 4: Evax liberty. El paquete del producto aparece de manera virtual modelado en 3D. El producto, una compresa, que nunca es nombrada como tal, se coloca en una mano y se introduce en una cubeta donde un líquido azul muestra su eficacia. Evidentemente eficacia virtual ya que todo el spot está realizado mediante postproducción en el que se combina imagen real (la de las actrices) con imagen computerizada.

${ }^{20}$ Miguel Borrás, M., Martín CASAdo, T.g. (2014): Los referentes cinematográficos en la creatividad publicitaria (spot de Chanel $n^{\circ} 5$ en su campaña con Nicole Kidman) En LIBERAL ORMAECHEA, S.; FERNÁNDEZ PEREA, P. Últimos estudios sobre Publicidad: de "Las Meninas" a los tuits / coord. por. Madrid, Editorial Fragua. 1ª Edición, 224-227. 


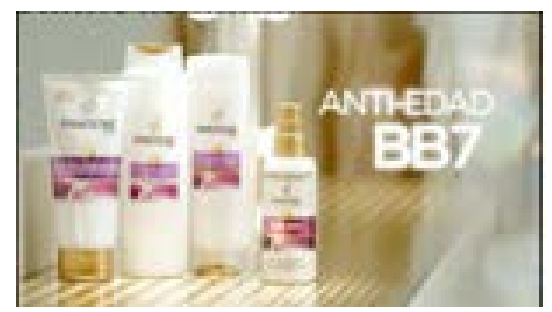

Spot 5: Pantene Pro-V Antiedad. El spot es todo compuesto por CGI, infografías del cuero cabelludo, de capilares. Cuenta con la actriz española Paula Echevarria que es la imagen del producto. Finalmente vemos el lote de productos, que de nuevo no son reales. Si no virtuales, con un filtro difuminador que los hacen parecer llenos de glamour.

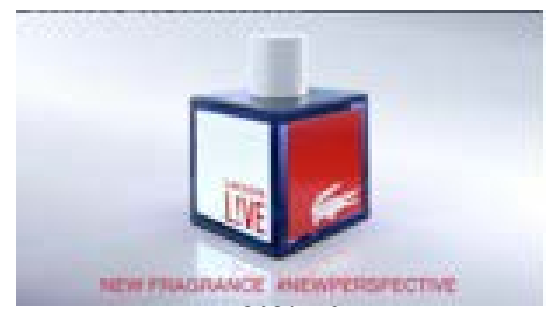

Spot 6: Colonia Lacoste L!VE, para hombres. El anuncio se utiliza una habitación donde dos operarios decoran todo una habitación con los colores y logotipos de la nueva colonia. Se utilizan los juegos de perspectivas al estilo M.C. Escher. con imagen real, apoyada por una postproducción en la transformación de la realidad al producto final de la fragancia. De nuevo el bote de colonia nos presenta una imagen virtual.

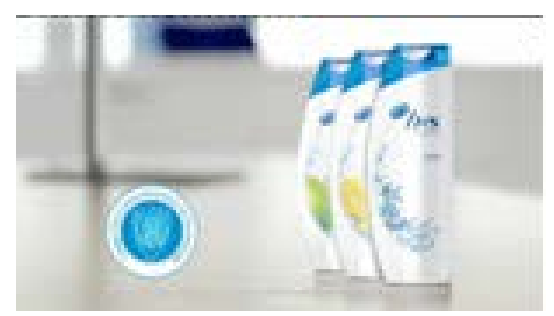

Spot 7: Champú Anticaspa H\&S. Una doctora, con nombre alemán que vemos en subtitulo, nos habla del cuero cabelludo y vemos una infografía de este. Finalmente el producto nos aparece virtualizado con tres botes infográficos del champú. 


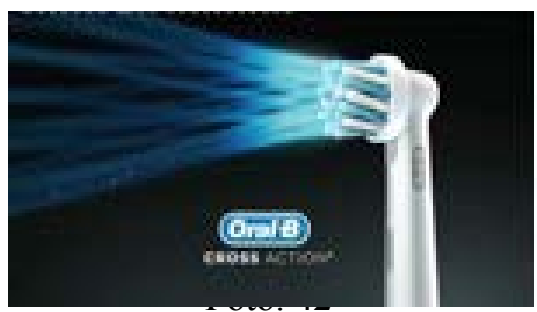

Spot 8: Cepillos de dientes Oral- B. Desde el inicio del spot estamos ante imagen CGI, las cerdas del cepillo resultan ser seres humanos. El cepillos se virtualiza para ver su efecto y manera de trabajar. Y finalmente como vemos en la foto, el cepillo emite una especie de luz, de nuevo mágica que lo hace especial y necesario.

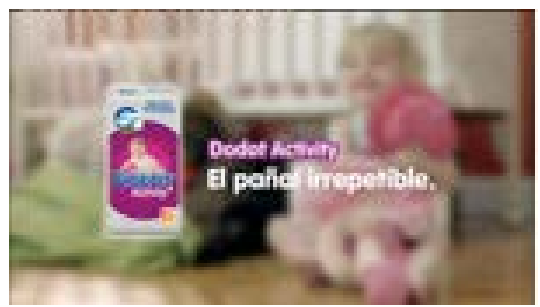

Spot 9: Dodot activity. Partiendo de una imagen a cámara lenta, que ya nos indica un concepto de postproducción en el vídeo. Del cuerpo del bebe sale un pañal virtual que de manera infográfica y con CGI se compone dicho objeto, un pañal, y se muestra su bondad. El paquete del producto de nuevo se crea de manera virtual.

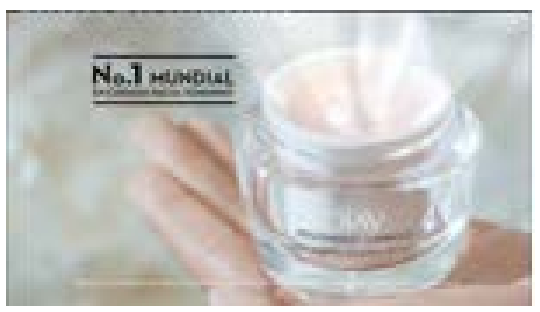

Spot 10: Crema Antiarrugas Olay. Usando la imagen real de distintas modelos que se miran al espejo y usando el producto. Todo es real, hasta que nos presentan su nuevo producto, que también emite luz. Es una crema prodigiosa o milagrosa para evitar lo más horrible, la vejez. Evidentemente las modelas que aparecen en el spot, ninguna es de edad avanzada y, por otra parte, están tratadas digitalmente del mismo modo que se trabaja el retoque en el medio impreso a partir de Photoshop. 


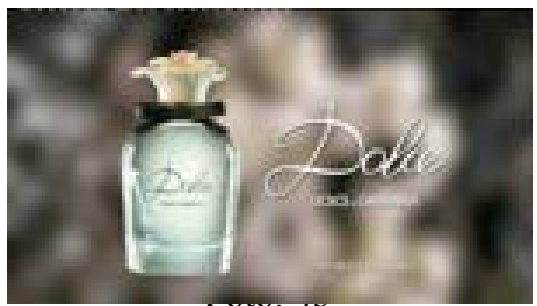

Spot 11: Colonia para mujer Dolce de Dolce \& Gabbana. Un spot que busca la inspiración cinematográfica ${ }^{21}$. El aire mediterráneo del olor de los naranjos y con un discurso visual tan antiguo como efectivo. Al presentarnos el producto es cuando nos encontramos con lo virtual. El bote de colonia es virtual.

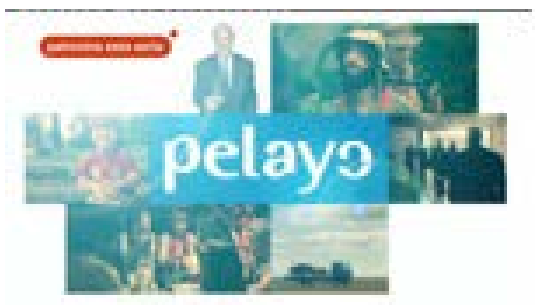

Spot 12: Aseguradora Pelayo. Esta compañía de seguros es la que patrocina el programa que estamos viendo. Un simple panel desplegable que se abre y en cada pequeña ventana que se abre aparecen imágenes de distintos anuncios visuales de la propia compañía. Por ejemplo la presencia del seleccionador de la selección española de futbol, que es imagen de la firma. Es un modelo de postproducción basado en el picture and picture. Se acompaña la imagen con unos reflejos y brillos para dar lustre al conjunto.

Como podemos vislumbrar en un breve bloque de publicidad televisiva elegido al azar, nos encontramos que el denominador común de todos los spots es esa presencia de la postrproducción. El CGI, reina en la publicidad audiovisual y es un elemento indispensable para la misma.

\subsection{El branded content, como un proceso de postproducción a gran escala}

El branded content es una forma de entender la publicidad que se está imponiendo y siendo tema de investigación y discusión en los últimos tiempos ${ }^{22}$. Sin ningún género

${ }^{21}$ Miguel Borrás, M., Martín Casado, T.g. (2014): «Los referentes cinematográficos en la creatividad publicitaria (spot de Chanel $n^{\circ} 5$ en su campaña con Nicole Kidman)» En LIBERAL Ormaechea, S. Fernández Perea, P (coord.). Últimos estudios sobre Publicidad: de "Las Meninas" a los tuits. Madrid, Editorial Fragua, 224-227.

${ }^{22}$ Eguizabal R. (2014): « Presentación» en Ron, R., Álvarez, A., Nuñez, P. (Coord.) (2014): Efectos de los contenidos de marca en niños y jóvenes. Bajo la influencia del Branded Content. Madrid. Esic Editorial. 13. 
de duda este tipo de publicidad se va a beneficiar de los procesos de postproducción. Entendemos este concepto como una mezcla entre representación espectacular (teatral, circense o cinematográfica) de la marca y el patrocinio. En donde esa marca va a estar presente en actividades para las que en principio nunca se habrían pensado y de una manera no intrusiva. La manera de que la marca aparezca en distintos espacios y representaciones es esa posibilidad que da la postproducción de manera técnica y conceptual.

Si revisamos la definición que plantea Nicolás Bourriaud de postproducción y que hemos expuesto en el inicio de este estudio, nos damos cuenta que el branded content es sin lugar un proceso de postproducción y que tiene muchos puntos de relación a esa Estética Relacional que propugnaba el francés.

\section{Conclusión}

La primera conclusión o, con toda probabilidad, la más importante es que la postproducción reina en el mundo de la publicidad audiovisual e impresa. El creativo y el realizador publicitario demandan una calidad máxima en la imagen del objeto referenciado, por lo que todo producto publicitario ha de ser tratado y repensado a través de la postproducción. Incluso, esta forma de entender la imagen publicitaria como construcción artística en la que el producto es el objeto referencia que el espectador debe contemplar casi con veneración, es una excusa para que, en algunos casos, se fuerce la falta de postproducción como la diferencia de un determinado producto frente al resto. En esta dirección, es previsible la aparición de formas de producción publicitaria que renieguen del proceso de postproducción. La llamada de lo analógico frente a lo digital como una manera estética de representar la esencia o la pureza frente a la manipulación del propio objeto.

De un modo u otro, cualquier imagen publicitaria, en la actualidad, pasa por un proceso de retoque y postproducción, necesario para situarla y diferenciarla frente al resto de imágenes. Esta Era Postmoderna es también la era de la postproducción, en la que el producto mágico al estilo del bálsamo de fierabrás es una constante en la mayoría de los objetos publicitarios. Esas características mágicas se hacen posibles por el uso de la postproducción.

Por todo ello, se instala como una parte fundamental del proceso formativo, la necesidad de que los nuevos estudiantes de publicidad conozcan el proceso de postproducción, con el objetivo de poder contar con el criterio suficiente para construir productos publicitarios que se encuentren plenamente situados e integrados en un contexto general, donde el brillo y la manipulación de la imagen a favor del mensaje, se convierten en el principal referente orgánico de las propias campañas. La formación debe tratar de suplir las carencias de conocimiento que la rutina diaria de trabajo no pueden contemplar, por lo que los planes de estudio deben tener la flexibilidad suficiente y necesaria para acomodar e integrar aquellas cuestiones que la industria demanda y sobre las que se debe reflexionar e integrar en el propio perfil del profesional del futuro.

En la nueva publicidad, el concepto de Branded Content puede ser entendido como un proceso postproducido. 


\section{Bibliografía}

Aguado Guadalupe, G. y García García, A (2009): Del Word-of-mouth al Marketing viral: aspectos claves de la comunicación a través de redes sociales. Revista Comunicación y Hombre. Número 5.

Bourriaud, N. (2007): Postproducción. Buenos Aires. Adriana Hidalgo Editores.

Bourriaud, N. (2006): Estética relacional. Buenos Aires. Adriana Hidalgo Editores.

BAUdRILlard, J. (1978): Cultura y simulacro. Barcelona. Kairós.

EguizÁBAL, R. (2011): Historia de la publicidad. Madrid, Editorial Fragua.

Eguizábal, R. (2012): Visiones ideales del consumo. Pensar la publicidad. Núm. Especial: Arte, Publicidad y Vida Cotidiana. Vol 6. Madrid, Universidad Complutense.

EguizÁBal, R. (2014): « Presentación» en Ron, R., Álvarez, A., Nuñez, P. (Coord.) (2014): Efectos de los contenidos de marca en niños y jóvenes. Bajo la influencia del Branded ContentK. Madrid. Esic Editorial.

Fernández Casado, J.l., Nohales Escribano, T. (1999): Postproducción digital. Cine y vídeo no lineal. San Sebastián, Ed. Escuela de cine y vídeo.

García Crego, J. y García Fernández, J. V. (2012): Teorías y Técnicas de Manipulación Humana. Madrid. Editorial Fragua. Colección Fragua Comunicación.

García Fernandez, J. V. (2008): Del fracaso amoroso. De la belleza. De la posmodernidad. Oviedo, KRK Ediciones.

García García, A. y Aguado Guadalupe, G. (2011): De un modelo de comunicación one-to-many a un mode-lo one-to-one en el entorno digital. Revista Iconol4 [en línea] 1 de enero de 2011, Año 9, Volumen 1. Recuperado (01/10/2014), de http:// www.icono14.net

Hervás Ivars, C. (2002). El diseño gráfico en televisión. Ediciones Cátedra. Madrid.

INFOADEX (2014): Estudio Infoadex de la inversión publicitaria en España 2014. Infoadex, Madrid.

Lodish, L.M., Morgan, H. L., Archambeau, S. (2007): Marketing That Works: How Entrepreneurial Marketing Can Add Sustainable Value to Any Sized Company. Wharton School Publishing.

Miguel Borrás, M.; Martín CASAdo, T. G. (2014): «Los referentes cinematográficos en la creatividad publicitaria (spot de Chanel $\mathrm{n}^{\circ} 5$ en su campaña con Nicole Kidman)». En Liberal Ormaechea, S.; Fernández Perea, P. (coord. Por): Últimos estudios sobre Publicidad: de "Las Meninas" a los tuits / Madrid, Editorial Fragua.

Moreno, I. (2003): Narrativa audiovisual publicitaria. Barcelona, Editorial Paidós.

Solana, D. (2010): Postpublicidad. Reflexiones sobre una nueva cultura publicitaria en la era digital. Barcelona, Autoeditado. 